\title{
Study of Chromium biosorption by Citrobacter freundii using scanning transmission $x$-ray microscopy
}

\author{
AMITH G ANIL $^{1}$, SUFAL SWARAJ ${ }^{2}$, D C PRABHAKARAN ${ }^{1}$ \\ PRAVEEN C RAMAMURTHY ${ }^{1}$, S SUBRAMANIAN ${ }^{1}$, SAJEEV \\ KRISHNAN $^{3}$, YANN SIVRY ${ }^{4}$
}

${ }^{1}$ Department of Materials Engineering, Indian Institute of Science Bangalore, India, onegroupb203@gmail.com ${ }^{2}$ Synchrotron SOLEIL L'Orme des Merisiers, Saint-Aubin BP-48 F-91192 Gif-Sur-Yvette Cedex, France

${ }^{3}$ Centre for Earth Sciences, Indian Institute of Science Bangalore, India

${ }^{4}$ Environomental Biogeochemistry, IPGP, Rue Jussieu, 75238 Paris Cedex 05, France

The elucidation of the mechanism of bio-reduction of $\mathrm{Cr}(\mathrm{VI})$ to $\mathrm{Cr}(\mathrm{III})$ assumes significance in the bio-remediation process. Previous works from our group have employed FTIR, EDS, and XPS to explain the mechanism. Scanning transmission X-ray microscopy (STXM) is a more direct analytical tool, which provides high resolution chemical speciation information down to $\sim 30 \mathrm{~nm}$. In this study, for the first time, STXM technique at SOLEIL Synchrotron facility was utilised to analyse the spatial distribution and chemical speciation of biosorbed chromium present on the Citrobacter freundii bacterial cells by image stacks and line scans at $\mathrm{Cr} \mathrm{L}-$ edge. Ratio of intensities at $577.4 \mathrm{eV}$ [Cr(III)] and $580.6 \mathrm{eV}$ $[\mathrm{Cr}(\mathrm{VI})]$ indicate that $\mathrm{Cr}(\mathrm{III})$ is predominantly present owing to bio-reduction. The ratio of $\mathrm{Cr} 2 \mathrm{p}_{3 / 2}(\mathrm{~L} 3)$ to $\mathrm{Cr} 2 \mathrm{p}_{1 / 2}(\mathrm{~L} 2)$ suggest that biosorbed $\mathrm{Cr}^{3+}$ is predominantly present in the form of oxides, hydroxides or oxyhydroxides $\left(\mathrm{Cr}_{2} \mathrm{O}_{3}\right.$,

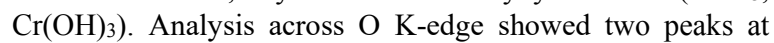
$531 \mathrm{eV}$ and $535 \mathrm{eV}$ with a sharp split around $533 \mathrm{eV}$, which is a characteristic feature of $\mathrm{Cr}_{2} \mathrm{O}_{3}$. A significant shift in 535 $\mathrm{eV}$ peak is observed for different regions of the sample indicating the effect of interaction of the bacterial cell with biosorbed chromium. Furthermore, it was observed that, varying concentrations of chromium does not alter the Cr Ledge signals as opposed by significant variation in the $\mathrm{O} \mathrm{K}$ edge signal. This supports the hypothesis that cell-bound oxygen atoms of hydroxyl and carboxyl groups are involved in chromium binding, reinforcing the FTIR spectral data. In addition, the elucidation of the molecular structure of the chromium binding unit will facilitate the design of selective sensors for chromium detection. 